This book, first published in Spring 1989, returns with a preface which surveys and comments on the Human Fertilisation and Embyrology Bill (now Act). The book contains eleven original essays aimed at 'student and lay person alike' but the variety and depth of subjects is likely to appeal to others, particularly academics and clinicians.

The book wins in several ways. It offers a rich mosaic of perspectives. Celia Wells conveys the agony of choice concerning the question of treatment of severely injured infants and seeks to justify non-treatment where continuation of life would not be in an infant's best interests. Derek Morgan sifts the stock of values and meanings surrounding surrogacy and Katherine O'Donovan illuminates how anonymity and secrecy are paralleled in adoption and gamete donation.

Her aim is to encourage critical analysis of the assumptions built into the responses of law and medicine to parentage. A similarly critical approach is forcefully presented by Robert Lee and Derek Morgan in their challenge to the courts' marshalling of facts in $\operatorname{Re} B$ in which the House of Lords upheld the authorisation of sterilisation on a severely mentally handicapped woman. In a separate essay Lee offers an equally pungent exposure of the hidden values which have directed the judiciary when deciding wrongful birth and wrongful life arguments.

Another of the book's values is the tension between approaches. Linda Clarke asserts a woman's right to choose whether or not to undergo abortion. The ontological status of the embryo or fetus is subsumed by the paramountcy of the woman's choice. John Harris, on the other hand, accepts the status of the embryo for the purposes of examining the ethics of embryo experimentation.

Most of the essays survey comprehensively the recent clinical and legal responses in particular areas. Frances Price offers a short review and comment on the medical profession's response to three problematic areas: multiple egg and embryo transfer, selective feticide, and egg donation by known donors. John Dewar examines the practice of and official responses to AID and reveals the male-centred shepherding of debate on the subject.

There are certain minor deficiencies in the book. For a volume entitled Birthrights, there is a noticeable lack of analysis of the language of rights. For example, Morgan and Lee speak of the right to reproduce as equivalent to the right to have one's reproductive capacities safeguarded. Yet the former may be wider than the latter. It may place an obligation on the state to facilitate reproduction. Only Elizabeth Kingdom addresses the difficulties in rights language; specifically, the problems for women in appeals to equal rights and the illusionary alternative of special rights, which may be no more than a sophisticated re-description of the former.

There is engaging variety and scope in this book, although Robert Lee is the only author who points to the economic map on which all these issues are located. His observations are timely and significant. The debate on birth is likely to be joined by the issue of resource allocation, with far-reaching implications for health care generally. On the whole, this book is a rich collection of stimulating responses to the complexities of and interrelations between law, ethics, and practice in the area of human reproduction.

DERMOT K FEENAN

Lecturer in Law and Ethics in Medicine, University of Glasgow.

\section{Keepers: Inside Stories from Total Institutions}

Sholom Glouberman, 148 pages, London, £9.95, King Edward's

Hospital Fund for London, 1990

This is a strange and, in the end, a rather unsatisfactory book. The author, in a short introduction, explains that his purpose in writing it (apart from a personal aspiration to "confront the most dreaded aspects of physical and mental decline and death') is to address the role of staff members in various forms of total institutions (a prison, a psychiatric hospital, a hospital for physically and mentally handicapped children, a geriatric wing in a long-stay hospital etc), whom he calls collectively 'keepers'. Glouberman claims, rightly, that in organisational literature the place of keepers is given little detailed study, or is treated in an oddly dehumanised way: 'We are reminded of schoolteachers who are thought by their pupils to have no life outside the classroom and the school. They are not really people and cannot have normal human relationships. They do not have the normal range of human emotions. Most especially they lack sympathy'. The present book is, then, an attempt to redress the imbalance, by presenting a series of twelve interviews conducted by the author with the 'keepers', ostensibly to explore some of the complexities of the keeper/inmate relationship. This is a promising idea, and a very useful book could have been written on what is clearly an important subject. Unfortunately this book does not do the job.

The interviews are tidily (though surely quite misleadingly) presented in the form of interviewee monologue, with all the questioner's promptings and inquiries omitted. This gives the reader the strange impression that all Glouberman's interviewees had the habit of jumping from one subject to another in an unpredictable way (a characteristic of 'keepers'?). Prior to each printed interview, however, the author sets out his thoughts on the interviewee. These comments do not just place the interview in context, but are often very strong in personal terms. Before we read the statement of a senior prison officer in a maximum security prison in response to the author's undeclared questions, the author warns us that: 'Here is a man who does lie .... You review what he says and take it that his real feelings are almost diametrically opposed to what he says. My guess is that the results are then not far wrong ...'. An interview with a different maximum security prison officer is prefaced by the comment: 'Mr Rathwell is a distinguished and somewhat military looking man of 60 . He has a quiet calm manner. He treats all convicts as prisoners of war'. Ironically, the author then claims that Mr Rathwell 'seems the least stereotypical' of the keepers. I was then left feeling unsure of who was doing the stereotyping and very distrustful of the author's summaries.

What this book is crying out for is a proper theoretical framework or rationale within which the material the author has gathered can be usefully examined and assessed. We need a much expanded introduction to the book, which would address the underlying issues in the inmate/keeper relationship, such as personal autonomy, control and surveillance, power and dependence and rolerestriction. As it stands, the whole project suffers from being much too subjective and impressionistic. In the end the only conclusion to draw (the author makes no attempt to offer one) is that 'keepers' (like interviewers) 'are human, too'! This does not take us very much further in getting to grips with the important issues underlying this book.

MARTIN WASIK

Faculty of Law, Manchester University, M13 9PL. 